\title{
CONSTITUIÇÃO FEDERAL: ACOPLAMENTO ESTRUTURAL ENTRE OS SISTEMAS POLÍTICO E JURÍDICO
}

\author{
Fernando Rister Sousa Lima ${ }^{1}$ \\ Sumário: 1. Introdução. 2. Premissas Fundamentais da Teoria dos Sistemas. 3. Constituição \\ Federal: Acoplamento Estrutural entre os Sistemas Político e Jurídico. 4. Bibliografia.
}

\section{RESUMO}

$\mathrm{O}$ artigo analisa a Constituição Federal como acoplamento estrutural entre os sistemas jurídico e político, utiliza-se da Teoria dos Sistemas, elaborada pelo sociólogo alemão Niklas Luhmann. O subsistema do Direito opera com base no código binário direito/não direito, já o sistema político opera com base no código poder/não poder. A Constituição Federal age como mecanismo de interpenetração permanente e concentrada entre os mencionados sistemas sociais, e promove uma solução jurídica à auto-referência do sistema político, ao mesmo tempo em que se fornece resposta política à auto-referência do sistema jurídico.

\section{PALAVRAS-CHAVE}

Acoplamento. Constituição. Sistemas.

\section{ABSTRACT}

The article examines the Federal Constitution as Acomplia structure between the legal and political systems, is used in the Theory of Systems, prepared

1 Professor do Departamento de Teoria do Direito da PUC/SP. Mestre em Direito pela mesma instituição. Foi pesquisador visitante na Universidade de Estudos de Lecce (Itália). Professor Adjunto do Centro Universitário - UniToledo, Araçatuba/SP.

$\star$

UNIBRASIL
UniBrasil - Faculdades Integradas do Brasil

Rua Konrad Adenauer, 442, Tarumã. CEP: 82820-540 Curitiba - PR - Brasil Telefone: 55 (41) 3361.4200

revistaeletronicardfd.unibrasil.com.br/ 
by the German sociologist Niklas Luhmann. The subsystem of law operates on the basis of binary code right / not right, because the political system operates on the basis of the code power / no power. The Federal Constitution acts as a mechanism for permanent interpenetration and concentrated among those mentioned social systems, and promotes a legal solution to self-reference of the political system at the same time that it provides political response to self-reference of the legal system.

\section{KEYWORDS}

Theory. systems. code. Binary

\section{INTRODUÇÃO}

Neste artigo, tratar-se-á da Constituição Federal de 1988 como um acoplamento estrutural entre os sistemas jurídico e político, sem pretensões de cientificidade, tão-somente de cunho didático. A doutrina, principalmente a constitucional, investiga sobre aspectos jurídicos-dogmáticos a carta magna, contudo não é rotineiro encontrar-se trabalhos à perspectiva sociológica, quiçá à luz da Teoria dos Sistemas, elaborada pelo sociólogo alemão Niklas Luhmann, também conhecida por Teoria dos Sistemas "Autopoiéticos",2.

A referida doutrina procurou teorizar fundamentada na funcionalidade dos sistemas, na operação fechada, na cognição aberta e na elevada complexidade social. Quebra, por assim dizer, com normas pressupostas imaginárias, como, por exemplo, a norma fundamental Kelseniana, e desqualifica por completo o Direito Natural, de modo a propor descrever o sistema social global e seus respectivos subsistemas com base na diferenciação comunicativa, cuja operação tonar-se-ia possível reduzir a altíssima complexidade social, característica marcante das sociedades modernas. Para atender tal proposta, dividir-se-ão os itens em partes, a saber: 2 - PREMISSAS FUNDAMENTAIS DA TEORIA DOS SISTEMA; $2.1 \mathrm{O}$ objeto e a proposta da teoria dos sistemas; 2.2 A sociedade como sistema social complexo e contingente; 2.3 Os subsistemas sociais diferenciados, operacionalmente fechados, autopoiéticos e

2 CAMPILONGO, Celso. Governo representativo "versus" governo dos juízes: A “autopoiese” dos sistemas político e jurídico. Belém: UFPA, 1998. 
acoplados estruturalmente; 2.3.1 Os subsistemas sociais diferenciados; 2.3.2 A clausura operacionalmente dos sistemas; 2.3.3 Os sistemas autopoiéticos; 3 CONSTITUIÇÃO FEDERAL: ACOPLAMENTO ESTRUTURAL ENTRE O SISTEMAS POLÍTICO E JURÍDICO; 3.1. A Constituição Federal de 1988 como acoplamento estrutural entre os sistemas político e jurídico.

\section{$2 \quad$ PREMISSAS FUNDAMENTAIS DA TEORIA DOS SISTEMAS}

\subsection{O objeto e a proposta da teoria dos sistemas}

A formulação teórica luhmanniana autodescreve os processos e as estruturas da sociedade. Não busca dizer como "deve ser", mas como de fato é ${ }^{3}$. A comunicação é ponto-chave na sua teorização, inclusive, a própria sociedade é definida como comunicação. Por meio da reprodução comunicativa que se (re)produz as suas estruturas e a diferenciação sistêmica ocorre ${ }^{4}$.

A teoria sistêmica desenvolve-se em três vertentes, a saber: a comunicação, a evolução e os sistemas. A teoria da comunicação tem papel relevante, devido às operações dos sistemas serem tidas como comunicação e não como ação. A teoria da evolução aparece como forma de seleção, variação e estabilização e origina as diversas

3 Cf. MANSILLA, Darío Rodrigez. Invitación a la sociología de Niklas Luhmann. In: LUHMANN, Niklas. EI derecho de la sociedad. Tradução Javier Nafarrate Torres. México: Universidad Iberoamericana, 2002. p. 38-39. Ver BULLESBACH, Alfred. Ciência do Direito e ciências sociais. In: KAUFMANN, Arthur; HASSEMER, Winfried. Introdução à filosofia do Direito e à teoria do Direito contemporâneas. Tradução Marcos Keel; Manuel Seca de Oliveira. Lisboa: Fundação Calouste Gulbenkian, 2002. p. 409: "As teorias dos sistemas (ou sistêmicas) visam compreender a sociedade em conjunto (na sua totalidade). Especialmente em Luhmann, a teoria crítica da sociedade está relacionada com o interesse na análise da sociedade no seu todo.”. Também ver DE MICHELIS, Giorgio. Prefazione. In: MATURANA, Humberto R. VARELA, Francisco. Autopoiesi e cognizione. Tradução Alessandra Stragapede. Venezia: Marsilio Editori, 1985.

4 CAMPILONGO, Celso Fernandes. Política, sistema jurídico e decisão judicial. São Paulo: Max Limonad, 2002. p. 66. Ver BULLESBACH, Alfred. Ciência do direito e ciências sociais. op. cit., p. 411. Sobre o conceito de sociedade, ver LUHMANN, Niklas. Complejidad y modernidad: de la unidad e la diferencia. Edição e tradução Josetxo Beriain; José María García Blanco. Madri: Editorial Trotta, 1998. p. 59: "La sociedad es el sistema que engloba todas las comunicaciones, aquel que se reproduce autopoiéticamente mediante el entrelazamiento recursivo de las comunicaciones y produce comunicaciones sempre nuevas y distintas." Sobre a sociedade como comunicação, ver NAVAS, Alejandro. La teoría sociológica de Niklas Luhmann. Pamplona: Ediciones Universidad de Navarra, 1989. p. 148-149 e 153.

\begin{tabular}{|cl|}
\hline \multirow{2}{*}{$\begin{array}{l}\text { UniBrasil - Faculdades Integradas do Brasil } \\
\text { Rua Konrad Adenauer, 442, Tarumã. CEP: 82820-540 Curitiba - PR - Brasil }\end{array}$} \\
\hline Telefone: 55 (41) 3361.4200 \\
revistaeletronicardfd.unibrasil.com.br/
\end{tabular}


ordens sociais. A última é formada pelo conjunto integrado de conceitos, com intuito de teorizar sobre a sociedade e diagnosticar qual é a operação da sua autopoiesis ${ }^{5}$. Para tanto, deve ser capaz de compreender os fenômenos que ocorrem dentro da sociedade; explicar o sistema social de forma ampla; posteriormente, ser aplicada aos sistemas menores para construir as respectivas teorias. Seu autor cita como exemplo a Universidade Bielefeld, na Alemanha, e a empresa Coca-Cola ${ }^{6}$. Propõe-se sistemas auto-referenciais, organizados e reproduzidos por circulação interna de elementos do próprio sistema: um sistema fechado e independente. Baseia-se, entre outras influências, na teoria desenvolvida pelos cientistas chilenos Maturana e Varela, cuja tese central é de que as células humanas desenvolvem-se por elas próprias. Surgiu daí a nomenclatura: "autopoiético"7. O curioso é que os autores chilenos não estavam se referindo aos sistemas sociais; portanto, alguns estudiosos, como o próprio Luhmann, apontam uma mudança de paradigma quando do aproveitamento dessas referências ${ }^{8}$.

5 Cf. MANSILlA, Darío Rodrígez. op. cit., p. 39: "La teoría de la sociedad de Niklas Luhmann se desenvuelve en tres ámbitos teóricos que se van desarrollando paralelamente, pero con interconexiones entre sí. Estos son: la teoría de sistemas, la teoría de la comunicación y la teoría de la evolución.[...]. Ver VILLAS BÔAS FILHO, Orlando. O direito na teoria dos sistemas de Niklas Luhmann. São Paulo: Max Limonad, 2006. p. 101: “[...]é necessário lembrar que a teoria da sociedade, tal como Luhmann a concebe, está apoiada em elaborações teórico-conceituais advindas não apenas da teoria dos sistemas, mas também de uma teoria da comunicação e de uma teoria da evolução.[...]".

6 Cf. MANSILLA, Darío Rodrígez. Ibidem, p. 39: “[...]Luhmann señala explícitamente que, aunque la teoría de la sociedad se ocupa del sistema social más amplio - el que incluye todas las comunicaciones posibles -, no ahora el ámbito de lo social. Para el estudio de otros sistemas sociales - tales como las interaciones o las organizaciones - se requiere construir las respectivas teorías. No se puede pretender, por ejemplo, que las organizaciones (como la Universidad de Bielefeld o la Coca-Cola)".

7 CAMPILONGO, Celso Fernandes. Direito e democracia. 2. ed. São Paulo: Max Limonad, 2000. p. 73: "O neologismo, tão esotérico quanto as idéias de Luhmann, transporta para os sistemas sociais o conceito de autopiesis desenvolvido por Maturana e Varela para o exame dos sistemas biológicos. Esses sistemas seriam auto-referênciais, isto é, organizados e reproduzidos por meio de circulação interna de elementos inerentes ao próprio sistema.Maturama e Varela, a partir de um livro publicado em 1973, no Chile (De máquinas y seres vivos), desenvolvem a tese que os sistemas celulares possuem, internamente, todos os elementos necessários para o desempenho de suas funções fundamentais, inclusive auto-reprodução. Lidam, portanto, com um conceito de sistema fechado, auto-referencial, ou, conforme a terminologia depois consagrada, um sistema autopoiético.”. Ver RIBEIRO, Paulo de Tarso Ramos. Direito e processo: razão burocrática e acesso à justiça. São Paulo: Max Limonad, 2002. p. 149-150. Ver também NEVES, Marcelo. Entre têmis e leviatã: uma relação difícil. São Paulo: Martins Fontes, 2006. p. 60-61.

8 Cf. NEVES, Marcelo. op. cit., p. 61: “A concepção luhmanniana da autopoiesis afasta-se do modelo biológico de Maturana, na medida em que nela se distinguem os sistemas constituintes de

UniBrasil - Faculdades Integradas do Brasil

Rua Konrad Adenauer, 442, Tarumã. CEP: 82820-540 Curitiba - PR - Brasil

UNIBRASIL

Telefone: 55 (41) 3361.4200

revistaeletronicardfd.unibrasil.com.br/ 
Em verdade, pela autopoiesis, promove-se um filtro nos subsistemas sociais pelo qual nem todas as comunicações passam. Quando entram, irritam, o ambiente. Por isso mesmo, são chamados de sistemas operacionalmente fechados; entretanto, por exigirem troca de dados entre os ambientes distintos de outros sistemas, são classificados de sistemas cognitivamente abertos. Sua epistemologia produz-se uma razão interna. Busca integrar o sujeito e o objeto descrito, consequentemente a complexidade deste é reduzida ${ }^{9}$. A grande alteração, quando se compara com a sociologia tradicional, é a do padrão sujeito-objeto ${ }^{10}$. Em outras palavras, a Teoria dos Sistemas tem um foco diferente da aplicada à época, anos 70, à Teoria do Direito e à Sociologia ${ }^{11}$.

\subsection{A sociedade como sistema social complexo e contingente}

A complexidade é a totalidade de eventos possíveis. O mundo tornou-se imprevisível, dele podem surgir diversas situações ${ }^{12}$. Essa complexidade não é

sentido(psíquicos e sociais) dos sistemas não constituintes de sentido (orgânicos e neurofisiológicos)[...].".

9 DE GIORGI, Raffaele. Scienza del diritto e legittimazione. Lecce: Pensa Multimedia, 1998. p. 216. Ver VILLAS BÔAS FILHO, Orlando. op. cit., p. 43: "Para utilizar mais uma vez o jargão da teoria dos sistemas, pode-se afirmar que cada uma dessas elaborações teóricas não interpreta, mas constrói sua realidade.”. Ver Ibidem, p. 47.

10 Ver LUHMANN, Niklas; DE GIORGI, Raffaele. 11. ed. Milano: Milano: Franco Angeli, 2003. p. 16: "La trasformazione più profonda, che costituisce insieme anche il presupposto ineliminabile per la comprensione di quanto segue, consiste in questo: che non parliamo più di oggetti ma di distinzioni. Il rifiuto del concetto di oggetto ci permette non solo di rimarcare la distanza rispetto alle implicazioni connesse all'uso di schemi correlati a quel concetto, ma anche di avitare, negando ad essi fin dall'inizo qualsiasi spazio concettuale, quei presupposti di tipo sostanzialistico sui quali si è sorretta l'analisi sociologica, anche quando si sa svolta a livelli altamente formali." Ver LUHMANN, Niklas. Sistemi sociali. Traduzione Alberto Febbrajo; Reinhardt Schmidt. Bolonha: Mulino, 1990. p. 736. O interessante é que um dos tradutores da obra refere-se à autodescrição como o principal valor conceitual da Teoria dos Sistemas. Seria o princípio de fundo que consiste no nascimento e na materialização dos sistemas sociais. Cf. SCHMIDT, Reinhard. Appendice. In: LUHMANN, Niklas. Sistemi sociali. op. cit., p. 749.

11 DE GIORGI, Raffaele. Introduzione all' edizione italiana. In: La differenziazione del diritto. A cura di Rafaelle De Giorgi. Milano: Mulino, 1990. p. 22: "La teoria dei sistemi assume una prospettiva completamente diversa da quella sulla quale si erano attestate la teoria del diritto e la sociología del diritto degli anni '70.". Ver LUHMANN, Niklas. El derecho de la sociedad. p. 57.

12 LUHMANN, Niklas; DE GIORGI, Raffaele. op. cit., p. 219: "Per complessità del mondo Luhmmann intende la totalità degli eventi possibili. Il mondo è estremamente complesso laddove il margine di attenzione della nostra esperienza intenzionale e del nostro agire è estremamente

\begin{tabular}{|cl|}
\hline$\star$ & UniBrasil - Faculdades Integradas do Brasil \\
& Rua Konrad Adenauer, 442, Tarumã. CEP: 82820-540 Curitiba - PR - Brasil \\
\hline UNIBRASIL & Telefone: 55 (41) 3361.4200 \\
& revistaeletronicardfd.unibrasil.com.br/
\end{tabular}


planejada - para não dizer controlável - as relações sociais ganham certeza somente após ocorrerem. O futuro é imprevisível. Sobre o tema, Raffaele De Giorgi inicia um artigo, publicado no seu livro Direito, Tempo e Memória, com uma citação de Nietzsche: "Mundo: uma injúria cristã" e, à frente, continua a provocação ao indagar: este é o mundo da sociedade atual? Para que serve uma idéia de mundo? Isso para, em breves palavras, descrever todo o fenômeno pelo qual passou o Direito, a Política e a própria idéia de universalidade da razão humana; ressalta, De Giorgi, o século XIX, quando, pela referida expansão da racionalidade, pensou-se em igualdade (os homens seriam iguais) e todos seriam cidadãos do mundo. Cita, ainda, Marx que, embalado por esses ares, almejava unir os excluídos da sociedade. O século em deslinde (XIX) transcorreu pela razão do Iluminismo. Tentou-se assegurar racionalidade (ou ao menos se acreditava) na construção do bem comum. O fracasso dessas idéias logo veio à tona, como comenta De Giorgi: "Já no início do século a realização destas premissas tornou-se evidente, quando, no teatro do mundo - mundo da razão e da humanidade - começou, para usar a formulação hegeliana, a representação da tragédia na eticidade que o absoluto recita consigo. Uma tragédia que ainda continua."13.

A história mostrou que pensar em valores universais, em previsão do futuro (sejam nas políticas públicas internas ou externas de nações), controle da humanidade e nas revoluções em nome do bem comum são formas de promover a barbárie. A certeza que se tem quando se fala de Economia, em Direito, no amor e, por que não, em qualquer fenômeno social, é a incerteza do porvir. Complexidade e contingência são palavras de grande valor epistemológico na teoria luhmanniana: a primeira refere-se à realidade das ações. Dito de outra forma, diversidade de alternativas. Não se pode prevê-las e nem controlá-las; enquanto, na segunda, o futuro é apenas previsão, e não se pode esperar o seu acontecimento. Se, atualmente, temos "sim" como decisão, poderíamos ter o "não". A função de reduzir a complexidade do mundo é tarefa dos sistemas sociais, realizada pelo alto grau de diferenciação comunicativa ${ }^{14}$.

ridotto: la sovrabbondanza del possibile supera sempre ciò che noi siamo capaci di elaborare attraverso l'azione o l'esperienza.".

13 Condições de descrição da complexidade na sociedade mundial. In: Direito, tempo e memória, p. 210. Ver, sobre a crítica de Luhmann ao iluminismo racional, CAMPILONGO, Celso Fernandes. Política, sistema jurídico e decisão judicial. São Paulo: Max Limonad, 2002. p. 20. Porém, sobre a ruptura do modelo em estudo (luhmanniano) com a tradição humanista, ver Ibidem, p. 68.

14 Cf. DE GIORGI, Raffaele. Scienza del diritto e legittimazione. op. cit., p. 219. Ver Celso Fernandes Campilongo, Governo representativo versus governo dos juízes... Belém: UFPA, 1998.

\begin{tabular}{|ll|}
\hline \multirow{2}{*}{ UNIBRASIL } & $\begin{array}{l}\text { UniBrasil - Faculdades Integradas do Brasil } \\
\text { Rua Konrad Adenauer, 442, Tarumã. CEP: 82820-540 Curitiba - PR - Brasil } \\
\text { Telefone: } 55 \text { (41) 3361.4200 } \\
\text { revistaeletronicardfd.unibrasil.com.br/ }\end{array}$ \\
\hline
\end{tabular}


Ambas (contingência e complexidade) atuam no meio social, habitat do homem livre, vivente num mundo globalizado, no qual a comunicação de massa é incansável na divulgação imediata dos acontecimentos e o mercado torna-se cada vez mais voraz e dominador. A segurança, doravante, é representada pelas guerras: sejam as armadas, sejam as frias. Nos dias hodiernos, invade-se um país em nome da "paz". Atentados são realizados contra milhares de civis pela mesma "paz". Também há aquelas pessoas para quem o desarmamento é crucial à diminuição da violência, enquanto outras são a favor do armamento para o controle da mesma violência $^{15}$.

Dessa maneira, nova ordem instaurou-se e o racionalismo, então supostamente suficiente à construção da justiça, já não serve. A ótica da razão, cada vez mais, torna-se não-universal, mas coletiva, dividida em grupos unidos por diversos motivos, a saber: classes sociais, religião, etnias e, em alguns casos, o ambiente de trabalho. Numa linguagem teatral, a peça é outra!! A imprevisibilidade é a principal característica da sociedade atual. Por isso, é inegável a complexidade das operações sociais $^{16}$.

A formulação das expressões contingência e complexidade são tentativas de captar os problemas da vida social. Explicando novamente, essa é o fato de que sempre existem outras possibilidades além das já efetivadas. Por sua vez, por aquela se tem que as possibilidades apontadas podem ser diferentes das "apontadas", ou seja, têm-se duas opções igualmente legítimas à mesma situação. Luhmann relacionou a complexidade à seleção forçada e a contingência ao perigo de desapontamento $^{17}$.

p. 56. Ver ainda LUHMANN, Niklas. Sociologia do direito. op. cit., p. 225: "O crescimento da complexidade social, porém, fundamenta-se em última análise no avanço da diferenciação funcional do sistema social.". Ver ainda LUHMANN, Niklas. Sociologia del diritto. op. cit., p. 17. Quem trabalha, entre nós, com o conceito de sociedade, complexidade e contingência sob inspiração luhmanniana é Tercio Sampaio Ferraz Jr. ver Introdução ao estudo do direito. 4. ed. São Paulo: Atlas, 2003. p. 102.

15 Por um conceito luhmanniano de sociedade, ver CAMPILONGO, Celso Fernandes. Direito e comunicação de massa. In: $O$ direito na sociedade complexa, op. cit., p. 161.

16 Ver todo o raciocínio em DE GIORGI, Raffaele. Condições de descrição da complexidade na sociedade mundial. In: Direito, tempo e memória. São Paulo: Quartier Latin, 2006. p. 210. NEVES, Marcelo. op. cit., p. 16: "Por um lado, supercomplexidade envolve supercontingência e abertura para o futuro; por outro, provoca pressão seletiva e diferenciação sistêmico-funcional.".

17 Cf. LUHMANN, Niklas. Sociologia do direito. Tradução Gustavo Bayer. Rio de Janeiro: Edições Tempo Brasileiro, 1983. p. 44-46. Ver NEVES, Marcelo. op. cit., p. 15: "Com a pretensão de um modelo explicativo mais abrangente a respeito da emergência da sociedade moderna, Luhmann

\begin{tabular}{|cl|}
\hline \multirow{2}{*}{ औNIBRASIL } & $\begin{array}{l}\text { UniBrasil - Faculdades Integradas do Brasil } \\
\text { Rua Konrad Adenauer, 442, Tarumã. CEP: 82820-540 Curitiba - PR - Brasil } \\
\text { Telefone: } 55 \text { (41) } 3361.4200 \\
\text { revistaeletronicardfd.unibrasil.com.br/ }\end{array}$ \\
\hline
\end{tabular}


Há diversas pesquisas sobre a modernidade e o mundo. Segundo o sociólogo em questão, nenhuma delas foi feliz em tal tarefa devido ao fato de que a sociedade sofreu diversas modificações. Transformou-se da sociedade estratificada em sujeito autônomo dotado de dinamismo próprio, não reconduzido à soma da vontade individual, daí imprevisível. Desta forma, complexidade é a produção de diferenças novas ou ampliação de diferenças já realizadas como as principais consequências dessa nova sociedade ${ }^{18}$.

Como integrante do sistema social, essa complexidade social instaura-se também no sistema jurídico. Não se iludam os defensores da segurança jurídica. $\mathrm{O}$ Direito não pode garantir certeza. As comunicações jurídicas (como, por exemplo, os contratos, portarias, decretos - quaisquer gêneros legislativos - e sentenças judiciais), só apimentam a já complexa sociedade ${ }^{19}$. Pois bem, os atores referidos acima (contingência e complexidade) interpretam papéis na sociedade atual e, como tais, têm destaque no sistema luhmanniano ${ }^{20}$.

\subsection{Os subsistemas sociais diferenciados, operacionalmente fechados, autopoiéticos e acoplados estruturalmente}

\subsubsection{Os subsistemas sociais diferenciados}

Os sistemas parciais (ou subsistemas sociais) são construções comunicativas efetivadas por meio de suas operações (por exemplo, o Direito produz Direito), em que se garante a unidade do sistema. Tal formulação sistêmica decorre de pressupostos extraídos de outros campos científicos, tais como a Biologia e a Cibernética $^{21}$. Numa época em que não se tem uma unicidade de pensamentos, de

utiliza, em primeiro lugar, o critério da complexidade entendida como presença permanente de mais possibilidades (alternativas) do que as que são suscetíveis de ser realizadas.”.

18 Cf. DE GIORGI, Raffaele; CORSI, Giancarlo. Ridescrivere la questione meridionale. Lecce: Pensa Multimedia, 1999. p. 21 e 25.

${ }^{19}$ CAMPILONGO, Celso Fernandes. Direito e comunicação de massa. In: O direito na sociedade complexa. O direito na sociedade complexa. São Paulo: Max Limonad, 2000. p. 163.

20 Cf. DE GIORGI, Raffaele. Condições de descrição da complexidade na sociedade mundial. In: Direito, Tempo e Memória, op. cit., p. 210.

21 Cf. CAMPILONGO, Celso Fernandes. "Aos que não vêem que não vêem aquilo que não vêem”: sobre fantasmas vivos e a observação do direito como sistema diferenciado. In: DE GIORGI, Raffaele. Direito, tempo e memória. São Paulo: Quartier Latin, 2006. p. 18. Ver também CAMPILONGO, Celso Fernandes. Política, sistema e decisão judicial, op. cit., p. 67.

\begin{tabular}{|cl|}
\hline \multirow{2}{*}{ UniBrasil - Faculdades Integradas do Brasil } \\
& $\begin{array}{l}\text { Rua Konrad Adenauer, 442, Tarumã. CEP: 82820-540 Curitiba - PR - Brasil } \\
\text { Telefone: } 55 \text { (41) } 3361.4200 \\
\text { revistaeletronicardfd.unibrasil.com.br/ }\end{array}$ \\
\hline
\end{tabular}


crenças e consciências sociais, encontram-se sistemas sociais cada vez mais específicos, altamente diferenciados, com comunicações próprias. Pense num mundo formado e distinguido por sistemas e ambientes. Na medida em que se diferencia pela sua comunicação, somente o sistema pode se perguntar sobre as suas relações com o ambiente ${ }^{22}$. Torna-se, com isso, imprescindível a conceitualização da Teoria dos Sistemas. Com ela, a perspectiva sistemática resultante da sempre mutável diferença entre sistema e ambiente, a fim de produzir auto-observação ${ }^{23}$.

A divisão das estruturas sociais em sistemas é baseada na sua diferenciação, seja de comunicação ou de sua prestação, tudo sobre uma perspectiva luhmanniana ${ }^{24}$. E os sistemas sociais (direito, política e economia, citados à guisa de exemplo) desempenham funções específicas. Conferem um sentido e semânticas particulares à estrutura social. Permitem analisar as estruturas como funções e demonstrar a relação

22 Cf. CAMPILONGO, Celso Fernandes. "Aos que não vêem que não vêem aquilo que não vêem”: sobre fantasmas vivos e a observação do direito como sistema diferenciado. In: DE GIORGI, Raffaele. Direito, tempo e memória, op. cit., p. 20: "Entre o sistema (social) e o ambiente externo existem assimetrias marcantes. A unidade entre sistema e ambiente constitui o mundo. Ocorre que apenas no sistema o mundo e o ambiente podem ser conceitos de orientação. Trata-se de uma reintrodução da diferença no sistema. A diferença é imanente ao sistema. É com base na distinção sistema/ambiente, fruto de operações do sistema, que se torna possível construir a unidade do sistema. O re-entry ocorre quando o sistema trata sua distinção com o ambiente como se fosse uma distinção diversa. Apenas o sistema pode ser perguntar sobre suas próprias relações com o ambiente.".

23 BULLESBACH, Alfred. op. cit., p. 428: "No debate com as teses de Jean-François Lyotard (em Le Différend, Colection Critique, Paris, Minuit, 1983), Luhmann propõe, como solução do problema, que aquilo que o observador não pode ver seja introduzido de novo pela observação, isto é, pela observação do observador. A observação não se torna, por isso, na teoria sistemática de Luhmann, num produto da consciência, mas antes num conceito fundamental da teoria do sistema. A perspectiva sistemática, que resulta da sempre mutável diferença entre sistema e meio ambiente, produz, assim, um meio ambiente próprio, uma sua observação e uma descrição próprias da realidade; e, deste modo, também realidade própria. Assim, a consciência (sistemas psíquicos) e a comunicação (sistemas sociais) constroem meios ambientes respectivamente autónomos, não podendo ser reciprocamente redutíveis.".

24 CAMPILONGO, Celso Fernandes. Política, sistema jurídico e decisão judicial. op. cit., p. 66. Ver BULLESBACH, Alfred. op. cit., p. 410. Ver também LUHMANN, Niklas. Sociologia do direito. op. cit., p. 225. Ver ainda VILLAS BÔAS FILHO, Orlando. op. cit., p. 101: "cabe ressaltar aqui que é o próprio modo pelo qual a teoria dos sistemas concebe a sociedade moderna - ou seja, em termos de uma sistema autopoiético de comunicação que se caracteriza por uma diferenciação funcional em subsistemas auto-referênciais e autopoiéticos que, embora sejam cognitivamente abertos, são operacionalmente fechados e que realizam a redução de complexidade por meio de operações seletivas que são balizadas por códigos específicos, imutáveis e não passíveis de serem sobrepostos[...]".

\begin{tabular}{|ll|}
\hline \multirow{2}{*}{\begin{tabular}{l} 
UniBrasil - Faculdades Integradas do Brasil \\
Rua Konrad Adenauer, 442, Tarumã. CEP: 82820-540 Curitiba - PR - Brasil \\
\hline Telefone: 55 (41) 3361.4200 \\
revistaeletronicardfd.unibrasil.com.br/
\end{tabular}} \\
\hline
\end{tabular}


entre eles ${ }^{25}$. De outro lado, as antigas reflexões analíticas são objetos de pensamento. Por elas, nasce e se desenvolve uma ciência. Posto isso, percebe-se que a teoria da sociedade, sobretudo, valora os sistemas sociais, opera-os de forma diferenciada e desenvolve teorização complexa para atender uma sociedade igualmente complexa ${ }^{26}$.

\subsubsection{A clausura operacionalmente dos sistemas}

Por meio da clausura operacional, nada provém do exterior do sistema. A produção é interna e o sistema irrita-se quando em contato com outra comunicação. Como, por exemplo, a rejeição sofrida pelo sistema imunológico do organismo humano, quando é realizado um transplante e se constata que aquele órgão inserido não foi criado pelas células daquele corpo $^{27}$. Os estímulos e os distúrbios provenientes de outro ambiente são repelidos pelo sistema e, quando entram em contato, ativam-se operações internas ${ }^{28}$.

Os subsistemas têm as suas próprias comunicações. Motivo pelo qual um contrato - dentro do sistema econômico - efetua diferenciações fundamentadas nos preços; de outra forma, no sistema jurídico, vislumbrar-se-á se o previsto é válido ou

25 Ver DE GIORGI, Raffaele. La formazione del giurista. Politica del diritto. Ano XIV. n. 1., marzo 1983. p. 62.

26 Cf. LUHMANN, Niklas; DE GIORGI, Raffaele. op. cit., p. 24: "Secondo la concezione che qui deve essere sviluppata, la teoria della società è la teoria del sistema sociale complessivo, che include in sé tutti gli altri sistemi sociali. Questa definizione è quasi una citazione. Essa si riferisce alle proposizione introduttivi della Politica di Aristotele, che definiscono la comunità della vita cittadina (koinonía politiké) come la più importante (kyriotáte) comunità ci colleghiamo così alla tradizione vetero-europea perciò che riguarda il concetto di società. Naturalmente tutte le componenti della definizione (compreso il concetto di essere = periéchon, che noi scomporremo e sostituiremo con il concetto di differenziazione, proprio della teoria dei sistemi) saranno intense in modo diverso, perché ciò di cui ci occupiamo è una teoria della società moderna per la società moderna.".

27 Cf. MANSILLA, Darío Rodrígez. op. cit., p. 24: "El rechazo con que el sistema inmunológico responde a los transplantes de órganos, demuestra la capacidad del organismo de reconocer los elementos que él ha hecho y de reaccionar entre intento de incorporarle componentes que no han sido elaborados por él. Las células de las que está formado un organismo biológico han sito producidas por el mismo organismo, en total autonomía con respecto a su ambiente.”. Ver SCHUARTZ, Luis Fernando. Norma contingência e racionalidade. Rio de Janeiro: Renovar, 2005. p. 89-90.

28 DE GIORGI, Raffaele. Introduzione all' edizione italiana. In: LUHMANN, Niklas. La differenziazione del diritto, op. cit., p. 23: "Chiusura di un sistema significa che agli stimoli o ai disturbi che provengono dall'ambiente il sistema reagisce solo entrando in contado con sé stesso, attivando operazioni interne che vengono innescat dagli elementi dai quali il sistema è costituito.”.

UniBrasil - Faculdades Integradas do Brasil

Rua Konrad Adenauer, 442, Tarumã. CEP: 82820-540 Curitiba - PR - Brasil 
não. Nesse sistema, a comunicação é jurídica, e naquele a comunicação é econômica $^{29}$. Somente pela comunicação diferenciada os subsistemas adquirem unidade e fechamento operacional $^{30}$.

Os sistemas operativamente fechados, por permitirem a auto-organização dos sistemas parciais, são, na teoria luhmanniana, ponto-chave ${ }^{31}$. Entretanto, acarretam como consequência, a dependência de seus próprios atos para se organizar. O próprio subsistema organiza-se, as estruturas constroem-se e transformam-se mediante operações internas. Isso leva o axioma da clausura aos pontos mais discutidos na teoria: auto-organização e autopoiesis ${ }^{32}$. Poder-se-ia entender a autoorganização e a autopoiesis como expressões sinônimas. No entanto, são fenômenos diversos. A primeira diz respeito à construção e à operacionalização de estruturas dentro do sistema executadas por ele mesmo; a segunda significa determinação do estado posterior da operação a partir da limitação anterior ${ }^{33}$.

Para o funcionamento do fechamento operativo, tem-se a auto-organização como característica indispensável, mormente porque leva à construção e à transformação das suas próprias estruturas, mediante as suas próprias comunicações $^{34}$. O fechamento operativo não pode ser tido (em hipótese alguma),

29 Cf. LUHMANN, Niklas. L'informazione nell'economia e nel diritto. op. cit., p. 37: “Anche in questo caso le conseguenze del sistema sono totalmente differenti, in funzione che si consideri il diritto o l'economia. Il diritto contrattuale non effetua differenziazione seconde l'indicazione di prezzi, bensì alla luce di condizioni, le quali regolamentano se i contratti sono validi o non lo sono. Anche le differenti prospetive temporali svolgono un ruolo in questo contesto.". Sobre as diferenças operativas do sistema jurídico e do econômico, ver ainda ibidem, p. 28 e 33.

30 CAMPIlongo, Celso Fernandes. Política, sistema jurídico e decisão judicial. op. cit., p. 75: "Todos os subsistemas funcionalmente diferenciados possuem um código próprio que lhe confere unidade e fechamento operacional.".

31 Cf. BERIAIN, Josetxo; BLANCO. José María Garcia. Introducción. In: LUHMANN, Niklas. Complejidad y modernidad. Madri: Editorial Trotta, 1998. p. 13: "Así pues, hablar de sistemas autopoiéticos significa hacerlo de sistemas operativamente cerrados; esto es, de sistemas que no limitan la autorreferencial al plano estructural - un fenómeno del que se há dado cuenta en la teoria de sistemas com el término "autoorganización" - sino que la extienden al plano de sus operacines elementales.".

32 Cf. LUHMANN, Niklas. Introducción a la teoría de sistemas. Versão espanhola Javier Torres Nafarrate. México: Universidad Ibero Americana, 1996. p. 84.

33 Cf. LUHMANN, Niklas; DE GIORGI, Raffaele. op. cit, p. 22: "Le determinazioni concettuali alle quali fin qui siamo pervenuti chiariscono prima di tutto il concetto, oggi spesso usato, di chiusura operativa (o autoreferenziale) del sistema. Con questo concetto naturalmente non ci si riferisce a ciò che potrebbe essere inteso come di segregazione del sistema".

34 Ibidem, p. 31 e 40.

\begin{tabular}{|cl|}
\hline \multirow{2}{*}{ UNIBRASIL } & $\begin{array}{l}\text { UniBrasil - Faculdades Integradas do Brasil } \\
\text { Rua Konrad Adenauer, 442, Tarumã. CEP: 82820-540 Curitiba - PR - Brasil } \\
\text { Telefone: } 55 \text { (41) } 3361.4200 \\
\text { revistaeletronicardfd.unibrasil.com.br/ }\end{array}$ \\
\hline
\end{tabular}


como isolamento. Apenas as suas operações são executadas no seu interior - no caso do Direito, sempre pelo lícito/ilícito ${ }^{35}$. Em razão disso, nos sistemas, o acoplamento estrutural é o responsável pela troca de comunicações com outros sistemas. Traz irritação e gera nova comunicação ${ }^{36}$.

Simplificadamente, por sistemas operativamente fechados, entende-se: os sistemas que, para produzir as suas operações, remetem-se às suas próprias operações e reproduzem a si mesmos. O próprio sistema pressupõe a si mesmo ${ }^{37}$. Cada sistema parcial clausura-se fazendo as mesmas operações. Por esse motivo, no subsistema da ciência, o código é verdadeiro/falso. Por sua vez, no econômico, o dinheiro reespecifica-se pela sua comunicação ${ }^{38}$.

Como dito, mesmo com o fechamento operativo dos subsistemas e com a autonomia das operações, têm eles ligações entre si. São fechados em informação e abertos à energia. A forma de comunicar-se é pelas prestações. A política precisa do direito, e a recíproca é verdadeira; não sendo diferente à economia ou a qualquer outro sistema parcial. A prestação fornecida pelo subsistema ao outro é um ato de reciprocidade. Por exemplo, o subsistema das ciências efetua a sua função, mediante a produção de verdades, e faz prestações a outros mediante investigações aplicadas ${ }^{39}$.

35 NEVES, Marcelo. op. cit., p. 63: “Trata-se de autonomia do sistema, não de sua autarquia, nem de isolamento (causal). O fechamento operativo é, ao contrário, condição de possibilidade para abertura.".

36 Cf. LUHMANN, Niklas; DE GIORGI, Raffaele. op. cit., p. 31: "Ma non è affatto necessario respingere questa posizione in rapporto alla legge sull'entropia. Con 'chiusura' non si intende isolamento termodinamico, ma solo chiusura operativa, cioè il fatto che le operazioni proprie del sistema vengono rese ricorsivamente possibili dai risultati delle operazioni proprie del sistema." Ver ibidem, p. 33. Também ver CAMPILONGO, Celso Fernandes. Política, sistema jurídico e decisão judicial, op. cit., p. 67: "Fechamento operacional não é sinônimo de irrelevância do ambiente ou de isolamento causal. Por isso, paradoxalmente, o fechamento operativo de um sistema é condição para sua própria abertura. A relação entre os sistemas político e jurídico ilustra de modo exemplar esse conceito.".

37 Cf. LUHMANN, Niklas. El derecho de la sociedad. op. cit., p. 68: "Primero, pues, se hace necessario aclarar qué es lo que debe observarse (aunque se pretenda investigar las interdependencias entre sistema y entorno). Por operativamente clausurados deben definirse los sistemas que, para la producción de sus propias operaciones, se remiten a la red de sus propias operaciones y en este sentido se reproducen a sí mismos. Con una formulación un poco más libre se podría decir: el sistema debe presuponerse a sí mismo". Ver Ibidem, p. 99.

38 Cf. MANSILLA, Darío Rodrígez. op. cit., p. 47-48.

39 Ibidem, p. 49: "A modo de ejemplo: El subsistema de la ciencias - la ciencia de la sociedad efectúa su función mediante la producción de verdades comunicables, que son válidas para todos; cumple su prestación para otros subsistemas por medio de la investigación aplicada; y, finalmente,

UniBrasil - Faculdades Integradas do Brasil

Rua Konrad Adenauer, 442, Tarumã. CEP: 82820-540 Curitiba - PR - Brasil 
Um sistema operativamente clausurado pode ser descrito também como um sistema auto-referencial. A referência deve ser, pois, entendida no contexto de uma distinção, como descrição ${ }^{40}$. A auto-referência implica heteroreferência, e o sistema inicia-se mediante uma operação. Mostra-se como algo distinto do ambiente, posto que o sistema reflete a si mesmo, de forma a auto-realizar e autodescrever ${ }^{41}$.

\subsubsection{Os sistemas autopoiéticos}

$\mathrm{Na}$ comunicação luhmanniana, autopoiesis refere-se a um sistema autopoiético, o qual é tido como uma rede de produção de componentes e estruturas. Emissor da própria comunicação. Opera, por assim dizer, de forma auto-referencial. Implica auto-organização, quer dizer, elementos produzidos no mesmo sistema ${ }^{42}$. Em outras palavras, decorre da auto-organização da natureza e da sua comunicação com o seu ambiente, como se fossem células do corpo auto-regenerando ${ }^{43}$.

A origem etimológica da expressão é grega: autós (por si próprio) e poiesis (criação, produção). Os subsistemas produzem, e reproduzem, a sua própria organização circular, por meio de seus próprios componentes ${ }^{44}$. Além disso, os

realiza su reflexión en la investigación pura y en la continuidad o discontinuidad de sus propias tradiciones.".

40 Cf. LUHMANN, Niklas. El derecho de la sociedad. Tradução Javier Nafarrate Torres. México: Universidad Iberoamericana, 2002. p. 107: "Si se añaden otras consideraciones, un sistema operativamente clausurado puede ser descrito también con un sistema autorreferencial. En este lenguaje, la referencia debe ser entendida, en el contexto de una distinción, como descripción: cada distención dispone de un otro lado (siempre capaz de referencia).". Ver ibidem, p. 108 e 115-116.

41 Ibidem, p. 107: "Los conceptos observación y autoreferencia se implican mutuamente. Ya que por un lado, un observador sólo puede observar cuando puede distinguirse respecto de sus instrumentos de observación e de sus distinciones y descripciones, por tanto cuando él no se confunde permanentemente con sus objetos.".

42 Cf. MANSILLA, Darío Rodrígez. op. cit., p. 24. Ver também CAMPILONGO, Celso Fernandes. Política, sistema jurídico e decisão judicial, op. cit. p. 75: "Todos os sistemas funcionalmente diferenciados possuem um código próprio que lhes confere unidade e fechamento operativo. Esse fechamento, como insistentemente explica Luhmann, é condição para a abertura do sistema às referências do ambiente e aos programas de mudança no sistema.".

43 Cf. BULLESBACH, Alfred. op. cit., p. 430-431. Ver CAMPILONGO, Celso Fernandes, Governo representativo "versus" governo dos juízes. op. cit., p. 58: "Cada operação do Sistema jurídico parte da operação anterior e cria condições para operação seguinte, todas elas encerradas no mesmo código recursivo: a distinção direito não direito. Nisso reside o caráter autopoiético do direito moderno.".

44 Cf. BERIAIN, Josetxo; GARCIA BLANCO, José María. op. cit., p.11. Ver Bullesbach, Alfred, op. cit., p. 431: "Os sistemas autopoiéticos produzem continuamente, através do seu funcionamento, a

\begin{tabular}{|cl|}
\hline$\star$ & $\begin{array}{l}\text { UniBrasil - Faculdades Integradas do Brasil } \\
\text { Rua Konrad Adenauer, 442, Tarumã. CEP: 82820-540 Curitiba - PR - Brasil } \\
\text { UNIBRASIL }\end{array}$ \\
$\begin{array}{l}\text { Telefone: } 55 \text { (41) 3361.4200 } \\
\text { revistaeletronicardfd.unibrasil.com.br/ }\end{array}$ \\
\hline
\end{tabular}


sistemas autopoiéticos são sistemas abertos ao futuro, teleológicos, tendo a possibilidade de projetar e de reclamar a própria finalidade. Quaisquer das operações realizadas são coligadas às suas antecessoras e às sucessoras ${ }^{45}$. Então, no sistema econômico pode-se encontrar uma diferenciação comunicativa ligada ao dinheiro, em que as suas comunicações só serão produzidas neste sentido, daí o termo diferenciado. Neste processo de remeter o sistema a si mesmo, pela comunicação, produzir-se-á a autopoiesis do sistema econômico: a economia produz economia ${ }^{46}$. Nessas auto-referências, além do controle da produção, tem-se a condução dos seus elementos, como algo gerador de unidade indisponível, levando os sistemas a serem independentes, praticamente auto-suficientes ${ }^{47}$.

Os sistemas autopoiéticos são aqueles produtores não só das suas estruturas, mas também dos elementos da sua composição, a partir de suas próprias estruturas; geram, pelo narrado, operações fechadas e autônomas ${ }^{48}$.

sua própria organização circular, que se mantém constante como entidade fundamental. Esta organização pode ser descrita como uma rede de produção das suas próprias partes constitutivas.]". Ver NEVES, Marcelo. op. cit., p. 60: "Etimologicamente, a palavra deriva do grego autós (por si próprio) e poiesis (criação, produção).Significa inicialmente que o respectivo sistema é construído pelos próprios componentes que ele constrói.".

45 Cf. LUHMANN, Niklas. L'informazione nell'economia e nel diritto. op. cit., p. 29: "Un confronto di questo tipo potrebbe essere effettuato in molti sensi. Vogliamo citare ancora solo un aspetto. I sistemi autopoietici sono sistemi aperti verso il futuro, sono teleologici. Ciò significa che non hanno alcuna possibilità di proiettare e di richiarmare la propria fine (telos).[...]".

46 Cf. CAMPILONGO, Celso Fernandes. "Aos que não vêem que não vêem aquilo que não vêem”. op. cit., p. 19: "Transações econômicas, por exemplo, relacionam meios (de modo específico, o dinheiro) que condensam formas (os preços). A referência a um meio de comunicação como o dinheiro remete o sistema a si mesmo: produz a autopoiesis do sistema econômico. Seculariza a economia. Confere-lhe racionalidade livre dos dados a priori provenientes do lado de fora do sistema. Não há na economia uma objetividade extra-social. Mercados são construções sociais.”.

47 Cf. BERIAIN, Josetxo; GARCIA BLANCO, José María. op. cit., p. 12: “Los sistemas autorreferenciales, por consiguiente, no sólo tienen sino que necesitan disponer, al menos, de la capacidad de controlar la producción y distintividad de sus elementos. En consecuencia, elemento del sistema es algo que representa para éste una unidad última, indescomponible. Es en este preciso sentido cuando Luhmann habla de sistemas autopoiéticos; es decir, de sistemas capaces de constituir los elementos de los que consisten a modo de unidades funcionales y de $\mathrm{x}$, en las relaciones entre ellos, referirse a la vez a esta autoconstituición, que es así continuamente reproducida.”.

48 Ver sobre MATURANA, Humberto. Cognição, ciência e vida cotidiana. Organização e tradução Cristina Magro; Victor Paredes. Belo Horizonte, UFMG, 2001. p. 174-176. Também ver LUHMANN, Niklas; DE GIORGI, Raffaele. op. cit., p. 21. Ver ainda BERIAIN, Josetxo; GARCIA BLANCO, José María. op. cit., p. 9: "En efecto; el tema por antonomasia del pensamiento occidental há sido la unidad como principio y final de todo discurso. Y cuando, com el tránsito a la modernidad,

UniBrasil - Faculdades Integradas do Brasil

Rua Konrad Adenauer, 442, Tarumã. CEP: 82820-540 Curitiba - PR - Brasil 
A visão dos sistemas como subsistemas em forma de bolas de bilhar acaba por afastar um pouco a simpatia por eles. Não é fácil aceitar os referidos sistemas sob a ótica de duas bolas de bilhar, grosso modo. Superado isso, fica curioso quando os dois sistemas tocam-se. Operam exatamente nesse ponto de contato. As duas bolas induzem à separação dos sistemas ${ }^{49}$.

Para Luhmann e De Giorgi, a grande contribuição fornecida à conceituação de sistemas autopoiéticos é a de Maturana: são sistemas produtores de si mesmos. Autocriadores de suas estruturas e dos seus elementos ${ }^{50}$. Sua autonomia abrange o plano estrutural e o operativo. O sistema constitui as suas operações em relação às próprias operações ${ }^{51}$.

A unidade da operação é imprescindível à produção de um sistema autopoiético, constitui e reproduz unidades emergentes e logra uma redução de complexidade frente às hipóteses possíveis ${ }^{52}$. Por tudo isso, a autopoiesis do Direito

la unidad ya no pudo entenderse como sustancia, entró en su lugar subjetividad. Bajo la denominación de sujeto, el pensamiento moderno ha concebido una unidad que sólo se fundamenta a ella misma y todo lo que hace, sino también a todo aquello que, como distinto de ella, es objeto de sus referencias (cognitivas u operativas). La significación de la figura originaria del sujeto (en singular) era, precisamente, la de servir de base a todo conocimiento y acción sin depender de un análisis de la sociedad." Consultar LUHMANN, Niklas. Sistemi sociali. op. cit., p. 727.

49 Cf. CAMPILONGO, Celso Fernandes. Governo representativo "versus” governo dos juízes: a "autopoiese" dos sistemas político e jurídico. op. cit., p. 53: "Os sistemas jurídico e político podem ser descritos, como faz Luhmann figurativamente, como duas bolas de bilhar. Um não se confunde com a outra. Porém, o jogo só tem sentido quando as duas bolas se tocam. A Constituição e as instituições representativas operam exatamente nesse ponto de contato. As duas "bolas" sugerem, de uma parte, a separação funcional dos sistemas e, da outra, um conjunto de prestações entre a política e o direito. Só nesse sentido um sistema depende do outro.”.

50 Cf. LUHMANN, Niklas; DE GIORGI, Raffaele. op. cit., p. 21: “A questo livello della discussione un momento nuovo è costituito dal contributo di Humberto Maturana, che ha elaborato il concetto di autopoiesi [...]": Ver MATURANA, Humberto R.; VARELA, Francisco. op. cit., p. 99: "L'insieme degli scopi esposto nell'introduzione è stato raggiunto. Mediante la descrizione dell’organizzazione circolare auto-referente del sistema vivente, e mediante l'analisi dei domini di interazioni che una simile organizzazione specifica, ho mostrato l'emergere di un sistema autoreferente capace di fare descrizioni e di generare, mediante interazioni orientanti con altri simili sistemi e con sé stesso, sia un dominio linguistico consensuale che un dominio di auto-coscienza: cioè ha mostrato l'emergere dell'observattore.".

51 Ver LUHMANN, Niklas; DE GIORGI, Raffaele. op. cit., p. 22. Ver LUHMANN, Niklas. El derecho de la sociedad, p. 118: "Siguiendo una propuesta de Francisco Varela se puede designar la unidad operativa de un sistema como "autonomía”. Gorden Pask corrobora.".

52 Cf. LUHMANN, Niklas. El derecho de la sociedad. op. cit., p. 117: "Cuando estas exigencias se cumplen, el sistema del derecho se establece con un sistema autopoiético. El Sistema jurídico

\begin{tabular}{|cl|}
\hline$\star$ & UniBrasil - Faculdades Integradas do Brasil \\
& Rua Konrad Adenauer, 442, Tarumã. CEP: 82820-540 Curitiba - PR - Brasil \\
\hline UNIBRASIL & Telefone: 55 (41) 3361.4200 \\
& revistaeletronicardfd.unibrasil.com.br/
\end{tabular}




\section{\& DEMOCRACIA}

Vol. 4 (2008)

garante que o sistema jurídico reconheça a si mesmo pelo estímulo normativo das expectativas, que são a base do processamento das suas comunicações ${ }^{53}$.

\section{CONSTITUIÇÃO FEDERAL: ACOPLAMENTO ESTRUTURAL ENTRE OS SISTEMAS POLÍTICO E JURÍDICO}

\subsection{A Constituição Federal de 1988 como acoplamento estrutural entre os sistemas político e jurídico}

A sociedade moderna é caracterizada também pela funcionalidade sistêmica. As comunicações diferenciam-se por meio de sua binariedade. Formar-se-ão vários subsistemas, conhecidos ainda como sistemas parciais. Cada qual caracterizado pela sua funcionalidade e por código próprio. Desses novos sistemas, interessam o político e o jurídico. O primeiro formado pela reiteração comunicativa poder/nãopoder, cujas seleções internas produzem comunicações próprias: leis, portarias, decretos etc. Sua produção vincula a sociedade, consequentemente o sistema jurídico recebe valores já escolhidos, tendo que atuar com base neles, com escopo de garantir a manutenção das expectativas normativas ${ }^{54}$.

Pelo fechamento operativo dos sistemas, pode-se ter a impressão do isolamento dos sistemas. Ledo engano. Estão interligados pelos chamados acoplamentos estruturais (Maturana utiliza tal nomeclatura). Exemplo típico é o cérebro ligado estruturalmente à vida das células cerebrais, interrompidas quando a vida cessa ${ }^{55}$. Não é possível um sistema autoprodutor que fique totalmente fechado. Pelo acoplamento estrutural encontra-se comunicação com os outros subsistemas ${ }^{56}$.

constituye y reproduce unidades emergentes (incluyéndose a sí mismo) que no existirían sin la unidad de operación. De esta manera, el sistema logra una reducción de complejidad singularmente propia, una operación selectiva frente a posibilidades inmensas que, aunque no se tomen en cuenta por ignorancia o por deliberación, no interrumpen la autopoiésis del sistema.”.

53 Ibidem, p. 149: "La autopoiesis del derecho se reconoce a sí misma por lo inealienable del estilo normativo de las expectativas - que son la base del procesiamento de las comunicaciones jurídicas.".

54 Sobre a função dos sistemas político e jurídico, ver CAMPILONGO, Celso. Governo representativo "versus" governo dos juízes: A "autopoiese" dos sistemas político e jurídico. op. cit., p. 58.

55 Ibidem, p. 50-51. Idem., L'informazione nell'economia e nel diritto, p. 31.

56 Cf. MANSILLA, Darío Rodrígez. op. cit., p. 50: "El acoplamiento estructural implica un aumento de cierras dependencias, con una mayor sensibilidad que permite irritaciones - o gatollamientos - 
Por conseguinte, os subsistemas desenvolvem certa sensibilidade para resolver determinados eventos em torno do ambiente. Produz coordenações pragmáticas de transparências entre os subsistemas, autopoiéticos, clausurados operacionalmente e acoplados estruturalmente ${ }^{57}$.

O coligamento estrutural vem assim chamado por representar ligações entre as estruturas do sistema. Pressupõe dois sistemas estáveis pela dinâmica. As estruturas próprias do sistema servem a um coligamento operativo; desta forma, há uma continuidade da autopoiesis do sistema de operação, garantindo-se a estabilidade temporal do sistema, na medida em que se passa de uma à outra operação $^{58}$. Os sistemas parciais precisam comunicar-se para buscar uma adaptação ao novo ambiente, por meio do acoplamento estrutural ${ }^{59}$.

A Carta Magna é o exemplo clássico de acoplamento estrutural. Promove a referida ligação entre o sistema jurídico e o político ${ }^{60}$. Funciona como fator de exclusão e inclusão. Acaba por incluir novos valores e excluir outros anteriormente impostos ao Direito; por outro lado, é tida como mecanismos de irritação do sistema por trazer nova comunicação ${ }^{61}$. Também a propriedade é um acoplamento estrutural,

provenientes de ciertos aspectos del entorno, unida a una mayor indiferencia respecto a otros. Este doble condicionamiento posibilita el sistema acorde con ciertos eventos de su entorno disminuyendo, al mismo tiempo, las posibilidades de destrucción.”.

57 Ibidem, p. 50: "Los subsistemas, por consiguiente, desarollan cierta sensibilidades: se sintonizan para resonar ante determinados eventos del entorno y con esto se produce lo que podríamos llamar una coordinación pragmática de intransparencias, entre subsistemas autopoiéticos, clausurados operacionalmente y acoplados estructuralmente a su entorno.”.

58 Cf. LUHMANN, Niklas. L’informazione nell'economia e nel diritto. op. cit., p. 32: "Il concettopressuppone dei sistemi, che ottengono la loro stabilità grazie alla propia dinamica. Le strutture proprie del sistema servono ad un collegamento operativo, ad una continuazione dell'autopoiesi del sistema da operazione ad operazione, quindi da momento a momento.". Ver SCHUARTZ, Luis Fernando. SCHUARTZ, Luis Fernando. Norma contingência e racionalidade. Rio de Janeiro: Renovar, 2005. p. 92.

59 Cf. MANSILLA, Darío Rodrígez. op. cit., p. 24: "Esto no quiere decir que el sistema pueda vivir con prescindencia de su entorno, en una suerte de burbuja al vacío. El sistema se mantiene permanentemente adaptado al ambiente, en lo que Maturana llama acoplamiento estructural. Al acuñar el concepto de acoplamiento estructural, Maturana persigue evitar algunas ideas asociadas a la adaptación con un proceso, en el sentido que un sistema debe adaptarse, buscar mejores niveles de adaptación y pude perder la adaptación conseguida.".

60 O exemplo é ofertado por Celso Fernandes Campilongo. Governo representativo "versus" governo dos juízes. op. cit., p. 53.

61 Cf. MANSILLA, Darío Rodrígez. op. cit., p. 51: "Los acoplamientos estructurales sólo funcionan con un efecto de inclusión y de exclusión. Una Constitución, por ejemplo, puede haber sido

\begin{tabular}{|cl|}
\hline$\star$ & UniBrasil - Faculdades Integradas do Brasil \\
& Rua Konrad Adenauer, 442, Tarumã. CEP: 82820-540 Curitiba - PR - Brasil \\
\hline UNIBRASIL & Telefone: 55 (41) 3361.4200 \\
& revistaeletronicardfd.unibrasil.com.br/
\end{tabular}


contudo, do sistema parcial do Direito com a Economia (ou vice-versa). É a base na qual a Economia diferencia-se enquanto sistema. Processa-se por meio do seu código binário: ter/não-ter ${ }^{62}$. Porém, a propriedade não faz parte da comunicação do sistema jurídico. Não é possível resolver pendências jurídicas com a Economia ${ }^{63}$.

Enquanto a propriedade encontra-se como base das operações econômicas, o mesmo raciocínio não é válido para o sistema jurídico. Existem decisões judiciais que nada têm a ver com a propriedade. Imagine a eliminação da propriedade: no sistema econômico, isso seria o seu fim. Não se pode dizer o mesmo em relação ao sistema jurídico. Nele, a propriedade é um objeto (como tantos) enfrentado pelas suas decisões; desta forma, ela não se trata de comunicação diferenciada ${ }^{64}$. Este raciocínio, promovidas as adaptações necessárias, pode ser aplicado aos contratos: o Direito quando os processa não atua segundo o pagamento ou não-pagamento - ou mesmo na linguagem do preço. Opera por identificar se é válido ou não e em quais termos ${ }^{65}$.

A Constituição Federal, o acoplamento estrutural (strukturelle Kopplung) entre os sistemas político e jurídico, age como mecanismo de interpenetração permanente e concentrada entre os mencionados sistemas sociais. Possibilita, pois, a constante troca de influências recíprocas entre os subsistemas, filtrando-as. Ao mesmo tempo em que inclui, exclui. Por assim dizer, promove uma solução jurídica à auto-referência do sistema político, ao mesmo tempo em que se fornece resposta política à auto-referência do sistema jurídico ${ }^{66}$.

aprobada en su texto, pero no funcionará se no puede evitar los efectos contrarios a la constitución de la violencia política sobre el sistema del Derecho. Estos acoplamientos estructurales, por otra parte, conforman mecanismos que son considerados de manera distinta por cada uno de los sistemas acoplados y de esta manera se consiguen las irritaciones o gatillamientos mutuos.".

62 Cf. LUHMANN, Niklas. L'informazione nell'economia e nel diritto, op. cit., p. 35-36.

63 Ibidem, p. 36: "Mentre la proprietà si trova alla base di tutte le operazionè economiche, il caso inverso non vale. Esistono decisioni giudiziali che non hanno niente a che vedere con la proprietà, come ad esempio molte del diritto penale, di quello familiare e del diritto costituzionale. L'economia non pertanto analogamente fondamento del diritto, come il diritto è fondamento dell'economia.".

64 Ibidem, p. 35-36.

65 Ibidem, p. 37-38. Vale o registro das relações temporais existentes entre os subsistemas em comento: no jurídico ele é muito lento, suas comunicações demoram e se caracterizam pela demora; antagonicamente na economia, chega-se à antecipação de valores futuros - basta pensar no que é feito na bolsa de valores.

66 NEVES, Marcelo. Entre têmis e leviatã: uma relação difícil. op. cit., p. 97-99. 
BERIAIN, Josetxo; BLANCO, José María Garcia. Introducción. In: LUHMANN, Niklas. Complejidad y modernidad: de la unidad e la diferencia. Edição e tradução Josetxo Berian; José María García Blanco. Madri: Editorial Trotta, 1998. p. 9-21.

BULLESBACH, Alfred. Ciência do direito e ciências sociais. In: KAUFMANN, Arthur; HASSEMER, Winfried. Introdução à filosofia do direito e à teoria do direito contemporâneas. Tradução Marcos Keel; Manuel Seca de Oliveira. Lisboa: Fundação Calouste Gulbenkian, 2002. p. 409-442.

CAMPILONGO, Celso Fernandes. "Aos que não vêem que não vêem aquilo que não vêem": sobre fantasmas vivos e a observação do direito como sistema diferenciado. In: DE GIORGI, Raffaele. Direito, tempo e memória. São Paulo: Quartier Latin, 2006. p. 11-26.

. Direito e Democracia. 2 ed. São Paulo: Max Limonad, 2000.

. Governo representativo "versus" governo dos juízes: A “autopoiese” dos sistemas político e jurídico. Belém: UFBA, 1998.

. O direito na sociedade complexa. São Paulo: Max Limonad, 2000.

. Política, sistema jurídico e decisão judicial. São Paulo: Max Limonad, 2002.

DE GIORGI, Raffaele. Direito, tempo e memória. São Paulo: Quartier Latin, 2006.

. Scienza del diritto e legittimazione. Lecce: Pensa Multimedia, 1998.

. Introduzione all'edizione italiana. In: LUHMANN, Niklas. La differenziazione del diritto. Milão: Società editrice il Mulino, 1990.

. La formazione del giurista. Política del diritto. Ano 14, n.1., marzo 1983.

. CORSI, Giancarlo. Ridescrivere la questione meridionale. Leche: Pensa Multimedia, 1999.

FERRAZ JR., Tercio Sampaio. Introdução ao estudo do direito. 4. ed. São Paulo: Atlas, 2003.

LUHMANN, Niklas. EI derecho de la sociedad. Traducción Javier Nafarrate Torres. México: Universidad Iberoamericana, 2002.

. Economia e diritto problemi di collegamento strutturale. Osservatorio "Giordano Dell" Amore"... n. 6. Milano: Cariplo, 1989.

. Introducción a la teoría de sistemas. Versão espanhola Javier Torres Nafarrate. México: Universidad Ibero Americana, 1996.

. La differerenziazione del diritto. A cura di Rafaelle De Giorgi. Milano: Mulino, 1990.

. Sistemi sociali. Traduzione Alberto Febbrajo; Reinhardt Schmidt. Bolonha: Mulino, 1990.

. Sociologia del diritto. A cura di Alberto Febbrajo. Roma: Laterza, 1977.

\begin{tabular}{|cl|}
\hline \multirow{2}{*}{$\begin{array}{l}\text { UniBrasil - Faculdades Integradas do Brasil } \\
\text { Rua Konrad Adenauer, 442, Tarumã. CEP: 82820-540 Curitiba - PR - Brasil }\end{array}$} \\
\hline $\begin{array}{l}\text { Telefone: } 55 \text { (41) 3361.4200 } \\
\text { revistaeletronicardfd.unibrasil.com.br/ }\end{array}$ \\
\hline
\end{tabular}


Sociologia do direito. v. 1. Tradução Gustavo Bayer. Rio de Janeiro: Edições Tempo Brasileiro, 1983.

Sociologia do direito. v. 2. Tradução Gustavo Bayer. Rio de Janeiro: Edições Tempo Brasileiro, 1985.

DE GIORGI, Raffaele. Teoria della società. 11. ed. Milano: Franco Angeli, 2003.

MANSILLA, Darío Rodrigez. Invitación a la sociología de Niklas Luhmann. In: LUHMANN, Niklas. EI derecho de Ia sociedad. Tradução Javier Nafarrate Torres. México: Universidad Iberoamericana, 2002. p. 23-55.

MATURANA, Humberto. Cognição, ciência e vida cotidiana. Organização e tradução Cristina Magro; Victor Paredes. Belo Horizonte, UFMG, 2001.

; VARELA, Francisco. Autopoiesi e cognizione. Tradução Alessandra Stragapede. Venezia: Marsilio Editori, 1985.

NEVES, Marcelo. Entre têmis e leviatã: uma relação difícil. São Paulo: Martins Fontes, 2006.

SCHUARTZ, Luis Fernando. Norma contingência e racionalidade. Rio de Janeiro: Renovar, 2005. p. 63-178.

VILLAS BÔAS FILHO, Orlando. O Direito na teoria dos sistemas de Niklas Luhmann. São Paulo: Max Limonad, 2006.

\begin{tabular}{|cl}
\hline$\star$ & $\begin{array}{l}\text { UniBrasil - Faculdades Integradas do Brasil } \\
\text { Rua Konrad Adenauer, 442, Tarumã. CEP: 82820-540 Curitiba - PR - Brasil }\end{array}$ \\
\hline UNIBRASIL & $\begin{array}{l}\text { Telefone: } 55 \text { (41) } 3361.4200 \\
\text { revistaeletronicardfd.unibrasil.com.br/ }\end{array}$ \\
\hline
\end{tabular}

